\title{
COMO SE FALA EM TÓQUIO: \\ PARA UMA PROPOSIÇÃO DE DIALETO METROPOLITANO
}

Mariko Kuno'

\section{O que se fala em Tóquio?}

A "variante de Tóquio" representa a língua japonesa e passou a ser considerada e ensinada como padrão, sem que se fizessem discussões pormenorizadas a respeito. Na definição da área de dialetologia, considera-se dialeto materno de um individuo a fala do local onde ele viveu desde o nascimento até os 12 ou 13 anos de idade, período de formação da linguagem do ser humano. Um dialeto se forma dentro de uma comunidade linguística estabelecida em uma determinada área e se transmite por herança. A área onde se fala determinado dialeto e a comunidade linguística que o utiliza constituem a base de estudo sistemático da pesquisa dialetológica.

Será possível afirmar, então, conforme se entende pela metodologia utilizada na pesquisa dialetológica até hoje, que existe um "dialeto de Tóquio"? Ou que existe um falante prototípico do dialeto de Tóquio? O que se chama de dialeto de Tóquio seria falado por quem, e em que área? Aqui começa o nosso problema.

Em primeiro lugar, analisemos as definições de termos apresentadas até agora pela dialetologia.

1. Professora doutora da Kokugakuin University, foi pesquisadora visitante do Centro de Estudos Japoneses da USP, em 2006. O presente texto é a versão traduzida da conferência proferida no XVII ENPULLCJ IV CIEJB, realizado em 31 de agosto e 01 de setembro de 2006, no CEJAP-USP, publicada nos Anais do referido evento (p. 27-38). 
- Língua-padrão e dialeto: explicar as diferenças entre língua e dialeto é tarefa difícil. Por exemplo, os dialetos de Tóquio e Osaka não guardam muitas diferenças entre si, mas os dialetos de Aomori e de Kagoshima são considerados muito distintos.

Ainda, mesmo dentro de um dado conjunto de dialetos, se se fala exclusivamente em dialeto, a compreensão mútua torna-se impossível. Por exemplo, dentro do mesmo conjunto de dialetos da região oeste do Japão, o falante de Quioto que não está acostumado a ouvir outros dialetos pode não entender o dialeto de Kochi; já o de Kochi pode não entender o dialeto Banshû da província de Hyogo, e assim por diante. Por seu lado, o português e o espanhol são tratados como línguas distintas, apesar de guardarem entre si diferenças menores que as existentes entre os dialetos de Aomori e de Kagoshima. Em se tratando dos dialetos de Ryukyu, então, até mesmo usuários do mesmo grupo dialetal têm dificuldades para se entender, se não forem moradores da mesma vila ou da mesma ilha. Não obstante, os dialetos de Ryukyu são considerados pertencentes à língua japonesa.

- Lingua-padrão [hyôjungo] e língua-comum [kyôtsûgo]: O que chamamos de língua-padrão é algo determinado de forma artificial. Indica, por exemplo, algo como "a língua francesa" Por definição, padrão significa uma forma ou modelo que deve existir. De acordo com os dicionários, o significado de "padrão" também contém as noções de "referência para decisões", "critério de comparação" e "marco" Para que se estabeleça um critério de comparação ou um marco, é necessário que alguém, em algum lugar, tome essa decisão. No que tange à língua japonesa falada, ainda não existe uma uniformidade em nível nacional. Além disso, o termo "padrão" indica a forma mais comum de determinado ente, como a "família-padrão", ou o "formato-padrão" No Japão, esse "padrão" tende a ser tomado como o ideal. Com isso, historicamente os dialetos têm sido tratados como variantes inferiores; para evitar esse tratamento é que se cunhou o termo "língua-comum"

- Lingua-comum e dialeto: o que se chama hoje de língua-comum surgiu da variante falada pela camada culta da região nobre de Yamanote em Tóquio, mas a variante desta região em si não é considerada a língua-comum. Elementos de cunho coloquial como - cchatta (corruptela de te shimatta, acabar de), okkochiru (cair) e mattsugu (de massugu, direto, reto) têm sido considerados como pertencentes ao dialeto de Tóquio, e não à língua-comum. A língua-comum surgiu de forma natural e espontânea, e difere da língua-padrão no ponto em que esta é produto de uma idealização, virtual, ao passo que aquela constitui uma linguagem realmente existente. Acontece que a língua-comum carrega interferências dos dialetos das diversas regiões, abrigando assim muitas variações.

O termo "dialeto $X$ " indica a totalidade do sistema linguístico de uma determinada região. Da mesma forma como se usa o termo "língua $X$ ", pode-se falar em 
"dialeto de Tóquio" para Tóquio, ou "dialeto de Kyushu" para Kyushu. Não se trata de apontar apenas vocábulos ou pronúncias especiais: palavras de uso comum em toda a extensão do território japonês (como atama - cabeça, ame chuva, iku ir etc.) também se incluem nos dialetos. Ocorre que, em geral, o termo "dialeto" é frequentemente usado para indicar vocábulos ou pronúncias especiais.

- -ben: sufixo usado junto com a especificação da região do dialeto, como em Sendai-ben ["dialeto de Sendai"] ou Osaka-ben ["dialeto de Osaka"]. Não é usado no ambiente de pesquisa.

- Namari ("sotaque"): termo genérico que expressa ocorrências linguísticas características de dialetos de determinados locais ou comunidades, considerados como fora do padrão. Diz um antigo provérbio japonês: "O namari é a identidade de uma região" Não se usa no ambiente de pesquisa.

- Período de formação da linguagem: é o período dos 2 ou 3 até 14 ou 15 (para alguns, 12 ou 13) anos de idade, durante o qual o ser humano adquire a linguagem. $O$ dialeto ao qual o indivíduo fica exposto durante esse período passa a ser seu dialeto materno. Há opiniões também de que a aquisição da estrutura de um dialeto se processa até cerca de 30 anos de idade.

\section{O surgimento de Tóquio, mudanças históricas, formação e deslocamento da população}

Descreveremos brevemente o processo pelo qual a cidade de Tóquio, na condição de capital do Japão, veio acumulando suas características.

A população de Tóquio é de 12.678.395 habitantes (dados de 01/06/2006). Os números de instituições de ensino superior são: 11 universidades nacionais, 1 universidade metropolitana, 52 universidades/faculdades particulares e 34 faculdades com cursos sequenciais [junior colleges]. Os estudantes dessas instituições vêm de todas as partes do Japão. Entre esses estudantes não se usa nenhum dialeto, a não ser a língua-comum; o mesmo ocorre nas aulas e palestras. Quando às vezes um ou outro professor aparece usando um dialeto ou de Tóquio ou da região Nordeste (Tohoku), torna-se assunto em todo o campus. Os universitários podem adquirir a língua-comum através de esforço consciente, ou podem, quase inconscientemente, esquecer-se do dialeto materno e alterar sua linguagem para o que é percebido como a língua-comum. Ou, ainda, pode surgir, dentro do campus, um novo linguajar, próprio dos universitários.

Das empresas de comunicação de massa que cobrem todo o Japão, mais de $95 \%$ têm sua matriz nos distritos especiais de Tóquio. Esse é um fator decisivo para a difusão do falar de Tóquio por todo o Japão. Textos jornalísticos são obviamente revisados em função da língua-comum; nos programas em que a conversação tem papel central, usa-se o falar considerado como língua-comum, exceto algumas palavras percebidas como de tal ou qual dialeto, e esse conteúdo é transmitido 
para todo o Japão. Note-se que tratamos aqui daquilo que é considerado como a lingua-comum: esse falar comporta consideráveis variações e instabilidades. Entre as emissoras locais de uma dada região, não se costumam utilizar os dialetos locais, dando-se preferência ao que é considerado como a língua-comum.

$\mathrm{O}$ centro das atividades econômicas também está em Tóquio. A região metropolitana de Tóquio responde por 1/6 do PIB do Japão, e aproximadamente $80 \%$ de todas as negociações de ações e títulos do país são realizadas na Bolsa de Valores e Títulos de Tóquio, atestando mais uma vez que também o centro da economia japonesa se encontra nesta cidade. Isso significa ainda que o falar de Tóquio se destaca dentro das atividades econômicas. A região dos distritos de Tóquio é o centro dos poderes Executivo, Legislativo e Judiciário, assim como é na área econômica.

Observemos agora a cidade de Tóquio do ponto de vista geográfico. A extensão de sua área é notável. O preço dos imóveis em Tóquio é um dos mais altos do mundo. Possuir uma casa dentro da região metropolitana de Tóquio é extremamente dificil. Isso leva ao crescimento das áreas residenciais no subúrbio, e do número de pessoas que se deslocam diariamente para a região metropolitana a trabalho ou a estudo. Por exemplo, distritos como o de Chiyoda, onde há alta concentração de escritórios, são bem conhecidos pela diferença fora do comum entre os números de suas populaçães diurna e noturna. Durante o dia, a população de Chiyoda é de 850.000 pessoas, e à noite esse número cai para 44.000 , o menor dentre todos os 23 distritos de Tóquio.

Muitas dessas pessoas que vão diariamente à metrópole para trabalhar, como por exemplo os moradores da província vizinha de Saitama, apesar de não serem moradores da região, desenvolvem um sentimento de pertencimento à metrópole, considerando-se cidadãos de Tóquio. Durante o período da bolha econômica, junto com a forte alta dos preços imobiliários na metrópole e nas regiões adjacentes, a área que comportava as residências dos trabalhadores de Tóquio chegou a se estender ao norte até Utsunomiya, na província de Tochigi, e a oeste até Numazu, na província de Shizuoka. Essas pessoas, que se mudaram de Tóquio mas continuam a frequentar a metrópole a trabalho, uma vez considerando a si mesmos como cidadãos de Tóquio, também deixam de adquirir os falares da nova localidade para onde se mudaram. Ainda, essas pessoas não são falantes dos dialetos tradicionais de Tóquio. Pode-se afirmar, dentro dessa perspectiva, que há uma propagação da consciência de pertencimento a Tóquio, bem como da língua da capital.

Vejamos agora o processo da confluência populacional para Tóquio. No período de rápido crescimento da cidade, em especial nos períodos anterior e posterior às Olimpíadas de Tóquio, houve um aumento na demanda por mão de obra na construção civil, que atraiu trabalhadores vindos de Kyushu e do Leste do Japão, muito valorizados e chamados de "ovos de ouro" No período da bolha econômica, com a forte alta dos preços de imóveis, a onda do "impulso para a capital" 
também chegou a outras regiões. Compôs-se uma infinidade de canções sobre a saída para a capital: começando com o verso "bokuno koibito Tôkyôe icchicchi" ["minha amada foi a Tóquio"] e outros títulos como Ora Tôkyôsa ikuda [Vou para Tóquio], de Yoshi Ikuzô, e "Momenno Hankachifu" ["Lenço de algodão"], de Ôta Hiromi, entre muitas outras. Nesse período, aumentou rapidamente o número de estudantes ingressando nas universidades e faculdades particulares de Tóquio. Após se formarem, essas pessoas passaram a trabalhar e residir em Tóquio e suas regiões suburbanas; como resultado, surgiu uma geração que cresceu, tendo a língua-comum como dialeto materno, sem conhecer os dialetos tradicionais de Tóquio.

A formação da cidade de Tóquio em si, assim como a de outras grandes metrópoles, originou-se da concentração de pessoas vindas de várias outras cidades. Primeiramente, quando Tokugawa Ieyasu estabeleceu o xogunato em Edo (antigo nome de Tóquio), essa cidade regional tinha, segundo Ôishi Manabu, cerca de 150.000 habitantes, e o que se falava no local eram os dialetos de Tôgoku [Região Leste], e em especial aqueles fortemente marcados pelas características do dialeto de Kantô. No período Edo, a cidade de Edo passa a abrigar o xogunato e as residências dos senhores feudais, tornando-se o centro político do Japão. Entretanto, Osaka era ainda assim o maior centro de consumo do país, sendo na época, conforme o dito "Sete partes da riqueza do Japão para Osaka", o centro da economia do país.

Passemos a observar a formação e o desenvolvimento da cidade de Edo. Tokugawa Ieyasu, nascido em Nishimikawa (atual Okazaki, província de Shizuoka), mudou-se do Castelo de Sunpu (localizado na cidade de Shizuoka) para o Castelo de Edo. Ieyasu estabeleceu o xogunato em 24 de março de 1603, dando início ao periodo Edo. A capital do Japão na época era Quioto, com Edo no entanto centralizando a atividade política. Essa cidade atingiu o desenvolvimento graças ao planejamento urbano do xogunato, e no início do século XVIII, Edo chegou a ser uma das cidades mais populosas do mundo, com mais de um milhão de habitantes.

Em 1867 o xogunato de Edo chegou ao fim, com a cidade mudando de nome para Tóquio em 1868. Com a volta de Tokugawa para Sunpu juntamente com seus vassalos, a população de Tóquio viu-se bastante reduzida por um certo período. Em 1869, o Imperador Meiji se estabeleceu no antigo Castelo de Edo. Burocratas de alto escalão e outros funcionários do governo, vindos de todo o país, incluindo-se muitos dos antigos membros do governo xogunal, passaram a viver à volta do palácio imperial, dentro da área interna contornada pela Linha Yamanote de trem. Em 1871, com a reforma da divisão administrativa do Japão (estabelecimento da divisão do pais em províncias), surgiu a cidade de Tóquio como unidade administrativa. Em 1880, o número populacional de Tóquio retomou a casa dos 700.000 .

O governo de Meiji, concomitante com a centralização de atividade política, promoveu uma concentração absoluta de forças na cidade de Tóquio, a fim de fazer 
face às superpotências europeias. No periodo Taisho, ano de 1920, a população da capital chegou aos 3.700 .000 habitantes. Em primeiro de setembro de 1923, porém, ocorreu o Grande Terremoto de Kanto, e em especial a região de Shitamachi de Tóquio [antiga região central da cidade, atualmente reduto tradicional de artesãos e comerciantes] foi severamente atingida. Relata-se que nessa região havia muitas pessoas residentes desde o período Edo, que teriam herdado a língua de Edo. Depois disso, a cidade de Osaka, apesar de ter superfície menor, passou a ser mais populosa que Tóquio, ficando com o status de centro econômico, industrial, cultural e artístico até cerca de 1937 Posteriormente, com a imposição do estado de guerra, todos os pilares da economia, indústria, cultura, arte, educação etc., passaram a se concentrar em Tóquio. Com o Grande Bombardeio a Tóquio durante a guerra no Pacífico, novamente o Shitamachi, com os herdeiros da língua de Edo, sofreram golpes devastadores.

Após a guerra, o governo japonês deu prioridade absoluta à reconstrução de Tóquio. Após os Jogos Asiáticos e as Olimpíadas, em meio ao desenvolvimento econômico acelerado, a cidade evoluiu como centro político e econômico, onde ocorreu um novo e grande crescimento populacional. Desse modo, continuou a grande centralização em Tóquio. A alta dos preços dos imóveis no período da bolha econômica também influenciou os moradores do Shitamachi. Por menores que sejam suas casas, a alta brusca dos impostos de herança obrigou-os a deixar suas residências e se mudar para Chiba, Saitama e outros locais ao longo da Linha Ferroviária Chûô.

Por fim, vejamos a que região se refere a denominação "Tóquio" Outrora, "Tóquio" se referia à "Cidade de Tóquio" [Tôkyô-shi], indicando o atual distrito central. Os moradores do distrito de Meguro, quando iam à Estação de Tóquio ou a Nihonbashi, diziam que estavam "indo para Tóquio" Porém, hoje em dia, quando se diz "região metropolitana de Tóquio" [Tôkyô-to], fala-se com o sentido de "província de Tóquio" [Tôkyô-ken], indicando a totalidade da região metropolitana (a antiga Tôkyô-fu), ou então os 23 distritos de Tóquio. Mais ainda, pesquisas apontam que entre muitos que não são de Tóquio, por exemplo, os habitantes das ilhas Hachijô ou de Okinawa pensam que locais adjacentes como as províncias de Saitama ou Kanagawa fazem parte da grande metrópole. A mesma confusão ocorre com relação às funções políticas de Tóquio. Em 1947, após a Segunda Guerra Mundial, as funções políticas da cidade foram interrompidas, mas o nome "Tôkyô-to" permaneceu. O governo de Tóquio acumula as funções de prefeitura (da cidade que abriga os 23 distritos) e de governo provincial, e até hoje permanece uma certa ambiguidade sobre sua denominação como governo provincial ou como prefeitura municipal.

\section{Formação e expansão da geração de falantes nativos da língua-comum}

Voltemos o olhar agora sobre as mudanças na língua. A evolução da língua de Tóquio pode ser descrita brevemente de acordo com o esquema a seguir: 
Dialetos do Leste $\rightarrow$ Língua de Edo $\rightarrow$ Língua de Tóquio $\rightarrow$ (dialeto da região metropolitana)

A característica mais marcante da língua de Tóquio é o rápido aumento numérico e variação populacional. A variação da população pode ser esquematizada como a seguir:

Início do período Edo: 150.000 habitantes $\rightarrow$ final do período Edo: 1.000 .000 hab. $\rightarrow$ do fim do xogunato até Meiji: 1.500 .000 hab. $\rightarrow 1.000 .000$ hab. $\rightarrow$ fim de Showa: 12.000 .000 hab.

Considera-se que nos meados do período Edo, no século XVIII, formouse a língua de Edo, mais refinada do que os dialetos de Kanto, e com influência também da língua de Quioto, a capital, uma vez que se aglomeravam pessoas de todo o país. De acordo com o Mapa dos Dialetos do Japão [Nihon Hôgen Chizu], constata-se a influência de língua de Quioto na de Edo: as escamas de peixe são chamadas predominantemente de koke em toda a região de Kanto exceto em Tóquio, onde se encontra a denominação uroko, a mesma usada nos dialetos de Kansai. Muitas outras influências similares são apontadas pelas pesquisas. À medida que se consolida a língua de Edo, os habitantes dessa região passaram a identificar a si mesmos como Edokko [gente de Edo], em uma postura de concorrência com a capital Quioto.

Com o fim do xogunato em 1867, o clã Tokugawa, bem como toda a classe dos guerreiros, retornaram a suas terras natais, e a população de Tóquio teve um rápido decréscimo por um certo período. Posteriormente, Tóquio recebeu o status de cidade e sua população teve um novo crescimento, e juntamente com isso fixaram-se os nomes Yamanote e Shitamachi. As denominações "língua de Yamanote" e "língua do Shitamachi" passam a ser amplamente conhecidas, mas com a migração das populações dessas regiões, as áreas onde se falavam essas línguas também sofreram variações. Primeiramente, a "língua do Shitamachi", herdeira da língua de Edo, viu seus falantes se reduzirem com o Grande Terremoto de Kanto e o Grande Bombardeio a Tóquio. Ainda, há depoimentos de que a dispersão das crianças em idade escolar dos Shitamachi para o interior no final da Segunda Guerra Mundial tenha contribuído para a assimilação de língua-comum dessas crianças nos respectivos locais de destino. $O$ deslocamento de pessoas do Shitamachi para os subúrbios na fase de rápido crescimento econômico também afetou o número de falantes de sua língua. Paralelamente, os dialetos tradicionais originalmente presentes em Tóquio (dialetos de Yamanote, do Shitamachi, de Kasai, de Kichijôji etc.) rapidamente deram lugar à língua-comum. A mobilidade e as condições sociais têm exercido forte influência na língua.

Mas, então, que dialeto pensam falar as pessoas que se consideram cidadãos da região metropolitana de Tóquio, por trabalharem ou estudarem nessa cidade? Elas não conhecem dialetos; não falam a língua de Yamanote nem a do Shitamachi; se obrigadas a responder, certamente dirão que falam a língua-padrão. A "língua- 
padrão" dessas pessoas é o falar do cotidiano, baseado na língua-comum. As pesquisas sobre novos dialetos também esclarecem que não se trata exatamente da língua-comum a que falam. Por exemplo, a palavra uzattai é famosa como uma palavra pertencente ao novo dialeto, mas na fronteira entre Tóquio e a província de Yamanashi, é usada como dialeto tradicional. Seu significado é " esquisito", mas nos últimos anos, vem sendo usada entre os jovens com o sentido de "trabalhoso, aborrecedor, que dá trabalho", assumindo as formas uzai ou uzê, e está se espalhando por todo o país.

Como expusemos até agora, dentro da população de 12.678 .395 habitantes (em 01/06/2006), são poucos os falantes dos dialetos tradicionais de Tóquio; mais que isso, esses dialetos não têm mais poder de influência sobre o falar de Tóquio como um todo. Atualmente, as pessoas que falam a língua-comum, próxima ao falar de Tóquio, utilizam-na no seu cotidiano. A maioria da população de Tóquio é originária do interior do país. Tomando-se essas pessoas como sendo a primeira geração, a Tóquio de hoje estaria na fase dos falantes de segunda e terceira gerações, que têm como dialeto materno a língua-comum falada pela primeira geração. Embora a língua-comum seja um falar compreensível a qualquer pessoa, livre da coloração dos dialetos, a falta de consolidação de expressões que respondam suficientemente às necessidades da atividade linguística cotidiana leva a uma assimilação periférica de expressões originárias de dialetos diversos, bem como à criação de novas expressões.

A geração de falantes nativos da língua-comum vem aumentando numericamente ainda hoje, tendo Tóquio como centro.

\section{Fatos sobre a língua de Tóquio da atualidade}

Neste item, apresentaremos alguns fatos que ilustram o estado atual da língua de Tóquio.

\subsection{Do mapa linguístico de Tóquio}

Dentre as não muitas pesquisas factuais que existem sobre a língua de Tóquio, temos o material produzido pela Associação de Pesquisas da Língua de Tóquio (Tôkyôto Gengo Chôsa Kenkyûkai). Trata-se de uma pesquisa que teve início desde 1988, por iniciativa do fundador e atual presidente da Associação e professor honorífico da Universidade Metropolitana de Tóquio (Tôkyô Toritsu Daigaku), Ôshima Ichirô. Atualmente, uma parte dos mapas linguísticos de Tóquio está prevista para ser publicada na internet, e a organização de dados e a compilação de mapas são feitas através da rede. Apresentaremos aqui uma parte desses mapas, com a permissão do presidente da referida Associação. Trata-se de uma pesquisa feita com duas gerações de falantes, na qual as diferenças entre as duas faixas etárias aparecem claramente, mostrando que a padronização da língua avança entre os falantes mais jovens, em detrimento das características tradicionais do dialeto de Tóquio. 

condições:

Os dados coletados pela referida Associação obedecem às seguintes

- Tanto os informantes mais velhos como os mais novos são do sexo masculino.

- Pelo menos um dos pais do informante é nativo da região do falante.

- Os informantes mais velhos têm por volta de 60 anos de idade, variando 5 anos para mais ou para menos.

- Os informantes mais novos têm por volta de 20 anos, variando 3 anos para mais ou para menos.

A pesquisa foi baseada nos dados coletados há quinze anos.

A partir do mapa linguístico, pode-se verificar primeiramente que o dialeto tradicional de Tóquio vem desaparecendo. Pela comparação dos mapas de distribuição da geração mais velha e da mais nova, percebe-se o desaparecimento de muitas manifestações peculiares do dialeto tradicional de Tóquio. Outrossim, percebe-se que as características até então ditas tradicionais do dialeto de Tóquio não são necessariamente uniformes. Por exemplo, a não-distinção entre os sons shi e $h i$, fenômeno amplamente conhecido como característico desse dialeto, não é constante mesmo entre os membros da geração mais velha, e tampouco é restrito à área da antiga cidade de Tóquio. Entre os mais jovens, a ocorrência desse fenômeno diminui drasticamente. Por outro lado, a pronúncia nasalizada de /g/, como [ $\mathrm{g}$ ] (gagyô bidakuon), é preponderante na geração mais velha; porém, embora seu declínio entre os mais jovens venha sendo apontado há muito, constata-se que não desapareceu por completo.

Por outro lado, existem manifestações dialetais que declinaram quase completamente. Por exemplo, o chokuonka (volta ao som básico do silabário ou supressão do som representado pela letra menor na escrita, de shu para shi), outrora muito conhecido como uma manifestação do dialeto de Tóquio, está quase desaparecido na geração mais jovem. O chokuonka era um fenômeno arraigado a ponto de aparecer escrito, nas primeiras tiras do cartum "Sazae-san" (de Machiko Hasegawa) no jornal Asahi, em que traziam a fala "Katsuo shikudai (shukudai) yatta?" ("Katsuo, fez a lição de casa?). Contudo está desaparecendo entre os falantes jovens. Igualmente a pronúncia de massugu (direto, reto) como mattsugu, considerada sem dúvida uma manifestação típica do dialeto de Tóquio, vem desaparecendo entre a geração mais jovem.

Em termos de variação fonética, quase $100 \%$ dos falantes da geração mais nova adquiriram a capacidade de pronunciar o som [fa]. É constatado que os falantes nativos de Tóquio pouco palatalizam shi, mas como há falantes da mesma região que o fazem igualmente com $j i$ e chi, é possível que se trate de uma peculiaridade tradicional do dialeto de Tóquio.

Os fenômenos tidos como típicos do dialeto de Tóquio não estão necessariamente presentes na totalidade da área da metrópole, e são crivados de 
exceções. Nos mapas também podem estar refletidas diferenças individuais ou estilísticas, vícios particulares de alguns dos numerosos pesquisadores envolvidos na coleta de dados, etc., como no exemplo seguinte: (Figura 1).

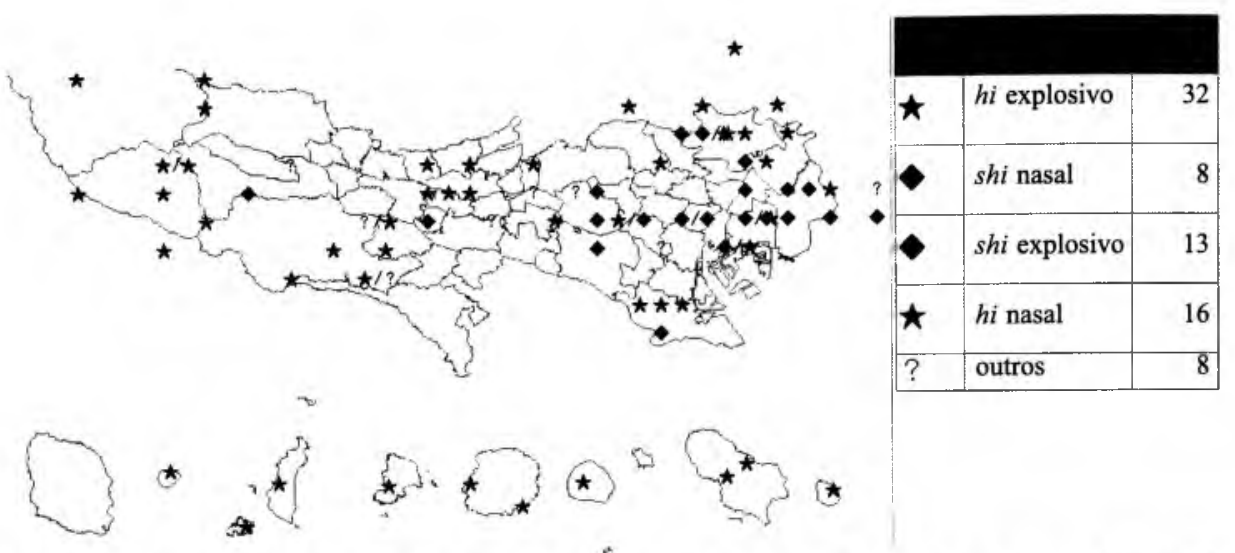

Figura 1. Mapa da distribuição da pronúncia de $h i$ como "hi" ou "shi" e de /g/ como [g] ou [y].

\subsection{Exemplos do dialeto da área metropolitana}

Propomos aqui chamar a língua de Tóquio, que engloba uma variedade de formas, de dialeto da área metropolitana.

Como variantes desse dialeto, citamos a linguagem dos jovens (wakamono kotoba) e a dos universitários (kyanpasu kotoba).

A seguir, apresentaremos os exemplos da linguagem dos jovens. $O$ fenômeno da criação de novas palavras e expressões por parte das gerações mais jovens ocorre em qualquer época, e sempre há entre os mais velhos quem reclame da distorção do uso de língua da parte dos jovens. As novas transformações linguísticas acontecem frequentemente entre as gerações novas. Dentro da linguagem dos jovens, há criações que desaparecem rapidamente, mas também há aquelas que levam diretamente a alterações da língua japonesa. A linguagem dos jovens e as mutações da língua-comum são chamadas de novos dialetos ou neodialect, entre outras denominações.

Incluem-se entre a linguagem dos jovens os modismos [ryûkôgo], gírias e jargões [ingo], a linguagem das colegiais [joshikôsei kotoba] e a dos universitários [kyanpasu kotoba]. Gostaríamos de chamar a atenção para alguns elementos dessas linguagens; não aqueles geralmente conhecidos, e por isso apontados e criticados, como o ra-nuki kotoba (omissão da sílaba ra do auxiliar rareru, com o sentido de possibilidade), mas aqueles que constituem mudanças linguísticas que ocorrem sem que os usuários em geral percebam. 
A linguagem dos jovens se constitui de usos novos, sobre os quais falantes de gerações anteriores não dispõem de quase nenhuma informação e que não constam nos dicionários; sua característica principal está no fato de que se trata de alterações da linguagem no nível do falar cotidiano, em que se dispensa a consulta aos livros. Lembramos que a chamada ranuki kotoba [supressão de ra do auxiliar rareru indicando "possibilidade", como em taberu (comer) $\rightarrow$ tabe(ra)reru (ser possível comer)] é, a rigor, uma mudança em que verbos do tipo -eru/-iru dão origem a verbos de possibilidade; estes vêm se integrar ao conjunto de verbos de possibilidade derivados daqueles do tipo - $u$, kuru e suru, acompanhando a tendência de evolução do japonês. Assim, pode-se dizer que, por mais que se tente evitar, mais cedo ou mais tarde, esse uso será reconhecido como correto.

A seguir, apresentaremos algumas mudanças, não aquelas que desaparecem rápido, como os modismos, nem aquelas criticadas a viva voz como o ranuki kotoba, mas sim as que passam despercebidas e estão a ponto de serem reconhecidas como japonês correto.

\subsubsection{Exemplo 1: o uso de sô nan da [É isso]}

Sô nan da, traduzido para o dialeto de Kansai, resulta em sô nan ya. Entretanto, entre os usos atuais dessa expressão, existe atualmente um que não permite essa tradução.

\section{- Uso original de sô nan da:}

Expressa concordância com o que diz o interlocutor, ou afirmação de um assunto.

Tiemi: Mada tesuto-chû na no?

Ainda está fazendo provas?

Masato: Sô nan daa ashita made. Hayaku asobitai yo.

Isso mesmo, até amanhã. Queria ir me divertir logo.

Pode-se substituir esse sô nan daa por sô nan desu, sô nan desu yo, sô na no yo etc.

\section{- Uso atual de $\underline{\text { so } \text { nan da: }}$}

Expressa admiração ou interesse do falante por uma informação nova que tenha ouvido ou um contexto que passou a compreender.

Tiemi: Ima baito nani shiteru no?

O que você está fazendo de trabalho temporário, agora?

Masato:Baito-dokoro ja nai yo. Ima tesuto-chû da yo.

Agora não é hora de trabalho temporário. Estou em época de provas.

Tiemi: Sô nan da!

É mesmo? 
Uchi no gakkô wa nikisei dakara kôki ni matomete shiken da yo.

$\mathrm{Na}$ minha escola os cursos são semestrais, por isso, as provas são todas feitas no segundo semestre.

Encontramos outro exemplo parecido com o dado acima: "USP nan da?" (dos exemplos de opiniōes e impressões de entradas de blogs). A frase é dirigida ao blog com o sentido de "quer dizer então que faz parte da USP, e não da Unicamp?" (não sabia, fiquei sabendo agora). Em blogs, registram-se primordialmente expressões da linguagem falada na escrita. Quem escreveu a impressão acima foi um rapaz descendente de japoneses de 26 anos, nascido em Campinas.

Esse uso de sô nan da não permite a substituição por sô nan desu, sô nan desu yo, sô na no yo, e vem se disseminando entre os jovens.

Além disso, também se aponta a distinção entre sô nan da "com interesse" e sô nan da "sem interesse"

Tiemi: Watashi, kondo, ryûgakusei shiken wo ukeyô to omou no.

Eu estou pensando em prestar exame para estudar no exterior.

Masato: [com interesse] Sô nan da (ii naa, yappari, boku mo ukeyô ka naa).

É mesmo? (que legal, acho que eu também vou prestar)

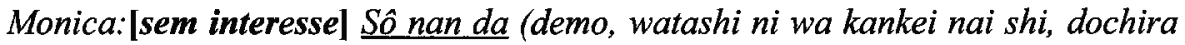
de mo ii koto da).

É mesmo? (só que eu não tenho nada a ver com isso, para mim tanto faz)

Os usos da expressão com ou sem interesse são distinguíveis entre si pela entonação. Da mesma forma, a entonação decrescente de $s h i$ em expressões como kankei nai shi, usada pelos jovens, indica que é inútil ou desnecessário continuar o diálogo.

\subsubsection{Exemplo 2: o uso de futsû ni}

De acordo com o dicionário Kôjien, o termo futsû ni significa: “1- algo amplamente conhecido. 2- Algo que pode ser visto em qualquer lugar. Comum. Geral."

No Meikyô Kokugo Jiten, constam: "1- algo que não tem diferenças relevantes em comparação com outros da mesma espécie. Não especial, ordinário. 2- Usual. Em geral. Normal."

Os usos a seguir não constam nem no Kôjien nem no Meikyô Kokugo Jiten, mas ocorrem entre os jovens:

1. Sorewa futsûni arienai -"isso é 'normalmente'[de fato] absurdo" (uma situação que se mostra naturalmente absurda para qualquer pessoa que a presencie).

2. Kono michitte futsûni semaishi abunaiyone - "Este caminho é 'normalmente'[realmente] estreito e perigoso, né" (qualquer pessoa que passe por aqui achará este caminho estreito). 
3. Kono eigawa futsûni tsumaranaiyone? - "Este filme é 'normalmente'[realmente] chato, não é mesmo?" (todos os que estão assistindo este filme devem estar achando chato).

4. Ore futsûni akaten ketteidayo - "Eu 'normalmente'[com certeza] vou tirar nota vermelha" (qualquer um que me conheça sabe que não deve sair outro resultado que a reprovação).

5. Ore dameda. Futsûni jishin nakushita - "Para mim não dá. Perdi 'normalmente'[totalmente] a autoconfiança" (Naturalmente perdi a confiança, por se tratar de uma situação em que qualquer pessoa consideraria natural que isso acontecesse).

6. (depois de comer algo saboroso) Kore futsû ni umai - "Isto aqui é 'normalmente'[muito] gostoso" (Algo que é naturalmente muito gostoso, irrepreensível para qualquer um que coma).

7. Repôto no shimekiri, futsû ni wasureteta - "O prazo do relatório, tinha me esquecido 'normalmente'[completamente]" (Tinha me esquecido completamente do relatório, como se fosse absolutamente natural que isso acontecesse).

Todos os exemplos acima trazem o significado de "como se fosse óbvio" ou "natural a ponto de qualquer pessoa concordar" Observando as co-ocorrências de futsû-ni com adjetivos, também constataremos que esse uso é frequente.

Por exemplo, ocorrem futsûni sugoi (impressionante), futsû ni kawaii (gracioso), futsûni okashii (estranho), futsûni yabai (enrascado), futsûni takai (alto), futsûni hikui (baixo), futsûni yasui (barato), futsûni koê (kowai) (aterrorizante), futsû ni nagai (longo), futsû ni mijikai (curto) e futsûni omoi (pesado), entre outros. Como se trata de um linguajar informal usado entre colegas, aparecem também ocorrências com gírias, como koê (de kowai, aterrorizante). Todos esses usos contêm o significado de "situação óbvia a ponto de ser imaginável para qualquer pessoa, de modo não especial mas sim óbvio" Torna-se difícil fazer a associação padrão com a acepção "geral" ou "médio" de futsîu, contida nos dicionários. Trata-se de um uso novo, não constatado na fala dos falantes de meia-idade ou de idade mais avançada. Como a forma lexical não se alterou, a mudança de significado ocorre sem ser explicitamente percebida.

\subsubsection{Exemplo 3: as caracteristicas fonéticas e a Gramática Fonética}

Os tons [akusento] da língua japonesa são geralmente caracterizados como "relações de tons altos e baixos, definidas de acordo com vocábulos ou unidades sintáticas"

Isso pode ser constatado observando-se os pares ou grupos de palavras do japonês que têm a mesma grafia, mas que são pronunciadas em tons diferentes. Alguns exemplos são os grupos furu (agitar / cair), tsuku (perfurar / chegar), kau 
(comprar / criar [animal]), hareru (inchar / melhorar o tempo), ame (chuva / céu/ bala), hashi (ponte / palitos para comer / extremidade), oshokujiken (vale-refeição / casos de corrupção) etc.

Os tons são considerados como definidos conforme os vocábulos ou unidades sintáticas. Já a entonação atua no nível da estruturação da frase. Ouvindo uma frase, avalia-se a parte a que se dá maior ênfase. Citemos os exemplos de Ueno Yoshimichi, que diz ter sentido certa estranheza ao ouvir a frase 1 a seguir.

1-ji[kan ni yoyû wo mot]te [kûkô ni oide kudasa]i

Favor comparecer ao aeroporto com antecedência.

\section{2- ji[kan ni yoyû wo mot]te kûkô ni oide kudasa]i}

(Idem 1)

Para um falante de japonês, a frase 2 soaria natural se o conteúdo do anúncio fosse "venha cedo ao aeroporto, porque a inspeção de bagagem está mais rigorosa" Não basta que os tons das palavras estejam corretos; a entonação da frase como um todo deve expressar um significado sintático coerente. É com base nesse ponto de vista que se desenvolvem as pesquisas sobre a relação entre fonética e gramática. Trata-se de um novo campo de pesquisa, chamado de Gramática Fonética. Existem outros itens gramaticais que podem ser compreendidos a partir de pistas dadas pela fonética. Por exemplo, certas situações condicionam determinadas entonações para os vocábulos. Ou ocorre elevação de tom quando se tem a atenção voltada para o final da frase. Também quando se pronuncia a frase separando-se as unidades sintáticas, é frequente ocorrer elevação do tom, como em final de frase.

Apresentaremos a seguir algumas tendências de pronúncia da faixa mais jovem dos dias de hoje. Não é possível saber ainda, contudo, se essas tendências se consolidarão como características da pronúncia do japonês.

1- Percepção de aii como ai:

taiikusai (festival esportivo) como taikusai

taiikukan (ginásio de esportes) como taikukan

Esse "erro" tem gerado riso entre os jovens, porque a entrada taikusai nos conversores de caracteres fonéticos para ideogramas dos celulares resulta na combinação dos caracteres de "corpo" e "malcheiroso"2. É fato que na prática a pronúncia seja $a i$, mas a materialização dessa pronúncia na escrita é uma tendência nova de mudança linguística.

2- Inversão entre $n(/ \mathrm{m} /)$ e $i$

Exemplo: de fun'iki (ambiente, "clima") para fuinki

2. N. do T: Os jovens japoneses utilizam intensamente o sistema SMS de mensagens de texto por telefone celular. As teclas do celular são associadas a caracteres fonéticos (kana), que vão sendo convertidos automaticamente para ideogramas (kanji), à medida que o usuário digita. Erros na digitação dos caracteres fonéticos resultam, naturalmente, na conversão para ideogramas diferentes dos que o usuário tencionava escrever. 
Essa alteração está bastante difundida entre os jovens da região metropolitana. Alguns estudantes chegam a questionar por que a palavra fuinki é escrita como fun'iki. Seria interessante saber se, paralelamente a esse fenômeno, não ocorre o seguinte, com os pares foneticamente parecidos:

- inversão entre vogal longa e $n(/ \mathrm{g} /)$

gen'in (causa) e geiin (beber desenfreadamente/bebedeira), seii (sentido verdadeiro) e sen'i (fibra), seiken (poder político) senken (antevisão)

\subsection{Amostras escritas da linguagem dos jovens}

A linguagem que os jovens utilizam e as linguagens de personagens ${ }^{3}$ não refletem necessariamente a realidade da língua japonesa moderna, mas se difundem na medida em que são reconhecidas como estereótipos pela comunidade de usuários do japonês. Incluem-se aqui diversas classes sociais, estilos de fala e situações.

Os blogs são um exemplo de material escrito em uma linguagem próxima da falada. Apresentamos aqui exemplos de blog, como um material de apoio para observar as variações da linguagem falada. Existem muitas variações estilísticas nos blogs mantidos por jovens. Um mesmo falante usa uma grande variedade de estilos para se dirigir a diversos tipos de interlocutores. Considerando-se os blogs como expressão próxima da linguagem falada, sua riqueza de variações existentes se percebe através dos diálogos pela internet.

\subsubsection{As diferenças entre a consciência linguística e a língua usada de fato}

Existem diferenças entre a forma como o falante percebe a língua e a forma como este a utiliza de fato. Nos blogs também há diferenças entre a linguagem considerada padrão e aquela que é efetivamente praticada, evidenciando que às vezes os usuários não estão conscientes das mudanças linguísticas.

Por exemplo, temos o uso de ore. Aponta-se que os jovens de sexo masculino têm deixado de utilizar boku como pronome de primeira pessoa, dando preferência para ore.

De acordo com Kinsui Satoshi (Universidade de Osaka), do ponto de vista da linguagem de personagens, boku tende a ser utilizado por estudantes "caxias", dos que costumam ser alvo de troça.

Vejamos uma amostra de blog. Citaremos um e-mail de um rapaz entre 25 e 29 anos de idade (reproduzido com a permissão do autor).

"Renraku arigatô gozaimasu. Mixi no ichibu wa mondai arimasen no de tsukatte kudasai. Demo, boku no nikki tte nanka ichiren no gengotekina nagare ga aru no deshô ka?

3 Em japonês, yaknwarigo. Linguagens carregadas de maneirismos, que caracterizam categorias de personagens fictícios, mas não são usadas na vida real. 
Ichiô, boku ga nikki de ki wo tsukatteru no wa,

- ore to iu hyôki wa, toshiue no hito ya moto okyakusan ga iru node sakeru

- ore wa, sugoku chikai shin'yû no mae nomi shika tsukaimasen.

- kôhai no mae demo erasô ni utsuritakunai node "boku" wo ishiki shite shiyô shite iru to omoimasu."

(Tradução: "Obrigado pelo contato. Não tem problema, você pode usar partes do Mixi. Mas, será que tem alguma coerência linguística no meu diário?

"Alguns cuidados que tenho no meu diário são:

- evitar a expressão ore, já que há [leitores] mais velhos que eu e exclientes;

- usar ore exclusivamente com amigos muito íntimos;

- também não quero parecer arrogante diante dos colegas mais novos, então procuro conscientemente usar boku.")

Citamos a seguir trechos do blog do mesmo autor do e-mail acima (grifei as expressões que consideramos como linguagem dos jovens e expressões da língua falada).

"Riaru onigokko shinai ka"!!

mixi mitete omoshirosô na komyu wo hakken. Sono na mo riaru onigokko. Yonaka ni Shibuya toka Yokohama de sôzetsu na kibo deno onigokko rashii. Nanka tanoshisô ja nai? Sanka shiyô yoo. To iu koto de, URL hattokimasu. 19:07 는 shitchattaa $\$$

19:30 Doragon: Dete wa mitai... ( $\omega$ ) demo oni no kao wakan no ka na?

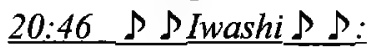

\section{$\star \star$ Minasan $\star \star$}

Nanka kore oni wa keikô no wakka wo tsukeru rashii. Chizu wo moraete, nde chûshajô ya shisetsu wa issai kinshi rashii. Teka, Yokohama de yattara zettai jitensha motte ikisô na ore daaaaa. Toriaezu, minna de sanka shiyô zee.

23:10 hiragon: Ore mo hashiruu!!

Ritz: Ii nee. Batabata hashirô zee.

Hiragon: nanka honki ni nattara hiragon ga meccha ganbarisô da yo ne. Rikujôbu datta yo ne???

(Tradução: "Vamos brincar de pega-pega real?"

Estava vendo o mixi e encontrei uma comunidade interessante. O nome é "pega-pega real" Diz que funciona num esquema gigante, de noite, em lugares como Yokohama e Shibuya. Não parece interessante? Vamos participar! Então, vou deixar o link. 
19:07 Tsuqu: O pessoal tem pegada, hein. Eu também já me registrei! 19:30 Doragon: Participar, eu queria... Mas dá para saber a cara de quem vai pegar a gente?

20:46 Iwashi

Pessoal,

Parece que o pegador usa uma argola fluorescente. Você ganha um mapa, e estacionamentos e instalações são totalmente proibidos. Na verdade, se for em Yokohama, com certeza vou acabar levando bicicleta! Bom, vamos todos participar para ver qual é!

23:10 hiragon: Eu também vou correr!!

Ritz: Legal, hein. Vamos correr adoidado!

Hiragon: Se a coisa ficar séria, com certeza o Hiragon deve correr muito mesmo. Ele era do atletismo, não era???)

Trata-se de um texto escrito, mas próximo da linguagem falada. O estilo é próximo ao usado nas conversações entre jovens conhecidos entre si. Os usuários são conscientes de que não se trata de um estilo necessariamente correto, nem que se deva usar em situações sociais. Nos blogs, são frequentes os diálogos escritos dessa forma, bem como os textos que são quase monólogos; nessa comunicação podem-se observar fenômenos como "erros" e desvios das normas da língua escrita.

\subsubsection{Variações no texto de um mesmo usuário conforme o interlocutor}

Também dentro do blog de um mesmo usuário, usa-se uma variedade de estilos conforme o interlocutor. Exemplo:

\section{k-san no nikki}

Ashita hikkoshi: sude ni, hotondo nanimo nai heya. Koko de kyô wa, chotto nokotta saigo no oshigoto shite kimashita.

[comentários à entrada no diário - interlocutor de idade igual ou inferior:]

08:44 toku-chan (colega mais nova da época do ensino médio):

Hikkoshi tte ie ka to omoimashita $\mathrm{f}^{\wedge}{ }_{-}$; (...) mata atarashii tokoro de mo ganbatte kudasai ne 约结

09:30 Haruna (colega da mesma idade da época do ensino médio)

Hikkoshi to wa??? Bôshiritsuchû no kôsha ga atarashiku naru no kashira $\searrow \quad+{ }^{\prime}(\bullet \vee \bullet)+*$

\section{k [resposta ao comentário - interlocutor da mesma idade:]}

>haruna: Aa, gokai sareteru... gomen nee, wakarinikukute sa. Bôshiritsuchûgaku wa, mada shigatsu kara kayoihajimeta bakkari da mon, sabishisa idaku hodo no aichaku ga, shôjiki, mada nai yoo ( ` ‘ ; Hikkoshi 
wa, $\boldsymbol{k}$ ga kayotte iru daigaku. Ima onboro da kara tatekaete kenkyûshitsu toka wo atarashiku surun da yoo.

[comentário à entrada no diário:]

19:48 NAAM (colega mais velho da faculdade):

Uwa! Ashita hikkoshi ka... Otsukaresama. Sore ni shite mo sabishiii. Sore wa sô to sono sukâto kawaii ne.

[resposta ao comentário:]

20:01 k (para o colega mais velho da faculdade)

Sô desu yo ne. NAAM san mo sabishii desu yo ne (kyôyô!?) !?!? (gaido no sukiru wa kore kara mi ni tsukemasu ( ' ' ;) \ soshite sukâto, homete kudasatte arigatô gozaimasu! Chôshi ni notte, kondo au toki haichaisô desu ( ' ')

[resposta ao comentário - colega da mesma turma na faculdade e do seminário de redação de trabalhos de conclusão]

$>$ Hakobee Yadaa! Hisashiburi jan, genki? Oisogashisô na noni gohômon arigatô‘ Sô sô, anta mo kekkô aikôshin arun da yo ne. Watashi mo omoide ga yomigaette kita yo. Daigaku no toki, natsukashii. Sabishii na... Demo demo, atarashiku natte mo mata asobi ni kite! Kangei da kara. Ganbatte saikaihatsu ni tsuite yukô!

[comentário à entrada no diário - colega do mesmo ano da faculdade] 01:05 Kawatchi: Sotsugyôshiki irai ittenai kedo, kôsha dondon atarashiku natterun da ne. Yappari omoide mo aru shi sabishii yo nee (>) Ano furubita kanji (笑, ideograma de "risos") ga uchi no daigakuppokute ki ni ittetan da kedo na.

Demo atarashii kenkyûshitsu, sugoshiyasui to ii ne ż̧

[resposta ao comentário - colega do mesmo ano na faculdade]

$>$ Kawatchi Sô ka, sotsugyô irai... Jâ 120-shûnen no tatemono mo sotsugyôshôsho mo morattakkiri da ne

Eki ni wa kite mo, daigaku ni wa yôji nai mon ne ( " ;

Sore ni shite mo daigaku no toki no omoide tte, Kawatchi kurai ganbattetara kanari kagayaiteru to omou $(><)$ ! !

(Tradução:

Diário de $k$

Mudança amanhã: Já não tem mais quase nada na sala. Então, hoje eu fiz uns últimos trabalhos que sobraram.

[comentários à entrada no diário - interlocutor de idade igual ou inferior] 08:44 toku-chan (colega mais nova da época do ensino médio):

Pensei que você estivesse mudando de casa $f_{-}^{-}{ }_{-} ;$(...) Bom trabalho no seu novo local 25 
09:30 Haruna (colega da mesma idade da época do ensino médio)

Que mudança é essa? Será que o prédio de certa escola particular vai ser

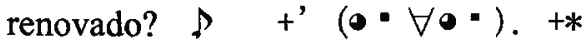

[resposta ao comentário - interlocutor da mesma idade:]

> haruna: Ah, estão me entendendo mal... Desculpem se estava difícil de entender. Essa certa escola particular, eu só comecei a frequentar desde abril, então sinceramente não tenho um vínculo afetivo a ponto de ficar

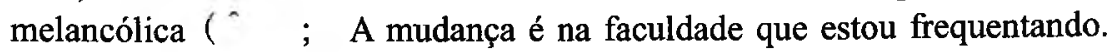
Como está caindo aos pedaços, vão reconstruir, e vão reformar os laboratórios e tal.

[comentário à entrada no diário:]

19:48 NAAM (colega mais velha da faculdade):

Nossa! Mudança amanhã... Bom trabalho. Mas é melancólico. Mudando de assunto, bonita essa saia, hein.

\section{[resposta ao comentário]}

20:01 $\mathrm{k}$ (para a colega mais velha da faculdade)

É mesmo, né. Você também está melancólica, né (forcei!?)!?!? (vou começar a aprender as habilidades de guia $\left({ }^{\prime} ;\right) \triangleright$ E obrigada pelo elogio da saia! Desse jeito eu me empolgo e acabo vestindo na próxima vez em que a gente se encontrar ( )

[resposta ao comentário - colega da mesma turma na faculdade] $>$ Hakobee Noossa! Quanto tempo, tudo bem? Obrigada pela visita, você que é táo ocupada 准 É mesmo, você também tem o maior carinho pela escola, não é? Eu também tive recordações. Tenho saudade da época da faculdade. Que triste... Mas, mesmo depois da reforma, venha fazer uma visita! Será bem-vinda. Força, e vamos acompanhar o novo desenvolvimento!

[comentário à entrada no diário - colega do mesmo ano da faculdade] 01:05 Kawatchi: Eu não vou lá desde a formatura, mas os prédios estão se renovando rápido, não? Realmente, a gente tem lembranças, é melancólico $(><)$ Eu gostava daquele ar antiquado (risos) que era típico da nossa faculdade...

Mas vai ser bom se o novo laboratório for confortável, néș

[resposta ao comentário - colega do mesmo ano na faculdade]

$>$ Kawatchi É mesmo, desde a formatura...? Então você só viu o prédio com 120 anos e recebeu o diploma, e nunca mais, não é?

Mesmo vindo até a estação, não tem o que fazer na faculdade, né ( ${ }^{\wedge}$; De qualquer jeito, as lembranças da faculdade, para alguém que se esforçou como você, devem ser bem brilhantes $(><)$ ! !)

$\mathrm{Na}$ amostra apresentada, podem-se observar as seguintes características. 
Primeiramente, usam-se os caracteres faciais ${ }^{4}$ entre colegas do mesmo ano ou de "veterano" para "novato", e mesmo de "novato" para "veterano" nos casos em que a relação é próxima a ponto de seu uso não ser considerado indelicado:

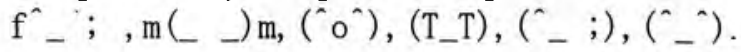

Os caracteres faciais acrescentam, aos textos de e-mail e da internet, informações como sons e expressões faciais. Trata-se de signos gráficos, porém diferem-se das letras, por não serem utilizados sempre com um mesmo significado.

Outra característica é a grande variedade de expressões na linguagem dos jovens, como neste trecho: "teka, jitensha motte ikisou na ore daaa. Sanka shiyou zee" Ainda, morfemas finais de frase considerados "rudes" mesmo para a linguagem falada são utilizados, quando a fala é dirigida a colegas mais novos. E uma peculiaridade na forma de expressar tons de ênfase no final das frases, com palavras e símbolos: 強要 (kyôyô - coação, ato de "forçar") !, 论, 放乡, $\circ \circ \sim$ D

$\mathrm{Na}$ amostra de blog acima foram omitidas algumas passagens em que a autora se dirigia aos colegas "veteranos" e professores; registremos aqui, porém, que nesses casos usou-se a linguagem polida (teineigo), e sem os caracteres faciais.

\section{Peculiaridades do dialeto metropolitano}

Considerando os aspectos expostos até aqui, propomos que se desenvolvam doravante as pesquisas da língua de Tóquio usada por pessoas cultas, levando-se em conta os seguintes fatores relacionados ao dialeto metropolitano:

1. O dialeto metropolitano é falado pelos habitantes não somente de Tóquio, mas também das adjacências, de onde vêm à capital a trabalho ou a estudo (Saitama, Chiba, Kanagawa).

2. O dialeto metropolitano é uma língua cujos usuários vindos do interior consideram que seja a língua-comum.

3. O dialeto metropolitano é muito próximo da língua-comum; entretanto, enquanto a língua-comum é compreendida por qualquer pessoa, sem que se destaquem características de qualquer dialeto, e usada na vida profissional, o dialeto metropolitano é usado na esfera pessoal, e por isso engloba não apenas a fala polida do ambiente profissional, mas também uma variedade de mutações, como vulgarismos, expressões grosseiras, gírias e palavrões. Incluem-se nessa variedade falares como a linguagem dos campi, a dos jovens e os jargões profissionais. Por exemplo, no dicionário da linguagem do campus da Kokugakuin University, temos o seguinte verbete: "aisu: denominação que engloba os significados de aisu kurîmu, sofuto kurîmu, aisu kyandî e shâbetto [respectivamente, sorvete, "creme gelado", picolé e sorbet]" O referido dicionário incorpora termos

4. N. do T.: em inglês, smileys ou emoticons, em japonês kaomoji. 
novos usados pelos estudantes no campus e também expressões usadas pelos jovens de modo mais amplo. Dentre essas expressões, há aquelas que logo caem em desuso, mas também há as que constituem sintomas de mudanças na língua japonesa.

4. As bruscas variações populacionais na região metropolitana têm grande impacto na língua. Isso pode ser considerado um fenômeno de mudança linguística comum às grandes regiões metropolitanas de todo o mundo. Como referência de pesquisa, podemos citar os estudos sobre a língua falada na cidade de São Paulo.

5. O dialeto metropolitano está em permanente mutação, assimilando novos vocábulos, expressões e entonações. Por exemplo, shindoi [esgotado de cansaço], ikan [não vai], sen [não faz] são originalmente expressões típicas do dialeto de Kansai, mas hoje são aceitas como parte da línguacomum / dialeto metropolitano, e usadas mesmo por falantes cultos. A formação de verbos potenciais (mireru "poder ver", koreru "poder vir", ukereru - "poder receber") a partir de verbos do tipo ichidan [verbos terminados em -eru ou -iru] é, atualmente, vista como desvio, mas uma vez que se considera parte da tendência de grande mudança da evolução histórica da língua japonesa, pode-se prever que um dia será oficialmente aceita.

6. O dialeto metropolitano herda a maior parte das peculiaridades da língua-comum e se apropria da mesma. Por exemplo, enquanto os dialetos regionais apresentam formas de expressão monolíticas, o dialeto metropolitano, assim como a língua-comum, apresenta expressões formadas pela junção de diversos morfemas. Por exemplo, são expressões monolíticas nakasaru (chorar espontâneo), do dialeto de Tôhoku, e yô oyogan ou oyogikiran (não sei nadar) do oeste do Japão; na língua-comum e no dialeto metropolitano, essas expressões tomam, respectivamente, as formas shizen ni nakete kuru e oyogu koto ga dekinai, que são compostas por vários elementos. Também há uma tendência à eliminação de exceções. Por exemplo, no dialeto de Tóquio, os verbos fuku (soprar) e fuku (enxugar / limpar) tendiam a ser pronunciados com o mesmo tom, devido a uma inclinação para o apagamento da vogal $u$ da primeira sílaba, que forçava o reposicionamento do tom alto na última sílaba; já os mais jovens, embora pratiquem o apagamento da vogal, optam por uma pronúncia distinta para cada vocábulo, ou dando tom mais alto à sílaba inicial, conforme se fazia originalmente, ou pronunciando as duas sílabas no mesmo tom. Isso pode ser interpretado como uma tendência a priorizar o sistema de posicionamento de núcleo de tons em detrimento do apagamento vocálico. 
7. $\mathrm{O}$ dialeto metropolitano inclui muitas das variações linguísticas que ocorrem em Tóquio. Uma das características desse dialeto é o uso de diferentes formas de falar dentro de uma mesma localidade, de acordo com a classe social dos participantes do diálogo e a situação da fala. Essa característica, de um mesmo indivíduo falar de formas diferentes conforme a situação e o interlocutor, é herdada do dialeto original de Tóquio. A variação é determinada por fatores como os que seguem: diferenças de idade (idade avançada, idade produtiva, jovens e crianças), diferenças de profissão (políticos, artesãos, comerciantes, militares, assalariados, profissionais de mídia, professores etc.), linguagem dos jovens (linguagem de campus, jargões profissionais, linguagem de estudantes femininas), neo-dialetos, palavrões, gírias, variações conforme a situação etc.

\section{Conclusão}

Existem diversas variações no japonês falado em Tóquio. Uma vez que a língua japonesa é mutável, é importante esclarecer o que ensinar e de onde obter informações para o ensino do japonês, tanto como língua estrangeira como língua materna.

É importante também considerar a língua, que sofre influência das mudanças sociais, de um ponto de vista estrutural, no contexto das relações dentro da sociedade.

No contexto da cultura japonesa, é igualmente importante analisar a língua japonesa de modo científico, incluindo sua relação com a sociedade. Para tanto, é necessário elucidar o estado da arte do dialeto metropolitano. No Brasil já se fazem estudos sobre a língua usada por falantes cultos. Acreditamos que abordagens sociolinguísticas como essa tragam subsídios valiosos para a pesquisa da língua japonesa. O português falado no Brasil reúne falantes ainda mais variados que o dialeto metropolitano de Tóquio, e ainda com as interferências das línguas maternas desses falantes. Em especial as pesquisas sociolinguísticas sobre o português falado em São Paulo, onde houve rápidos aumentos populacionais e se reúnem pessoas das mais diversas categorias sociais, devem fornecer subsídios importantes para o estudo do dialeto metropolitano dentro da língua japonesa. Desejamos que a pesquisa sociolinguística continue a se desenvolver em São Paulo, e que se apresentem ao Japão muitos estudos que venham a influenciar os estudos da língua japonesa, trazendo um próspero intercâmbio científico entre Japão e Brasil. 